\title{
Experimental study on waterflooding development of low-amplitude reservoir with big bottom water
}

\author{
Yanlai $\mathrm{Li}^{1} \cdot \mathrm{Jie}^{\operatorname{Tan}^{1}}{ }^{1} \mathrm{D} \cdot$ Songru Mou${ }^{1} \cdot$ Chunyan Liu $^{1} \cdot$ Dongdong Yang $^{1}$
}

Received: 9 June 2021 / Accepted: 19 August 2021 / Published online: 4 September 2021

(c) The Author(s) 2021

\begin{abstract}
For offshore reservoirs with a big bottom water range, the water cut rises quickly and soon enters the ultra-high water cut stage. After entering the ultra-high water cut stage, due to the influence of offshore production facilities, there are few potential tapping measures, so it is urgent to explore the feasibility study of artificial water injection development. The quasi-three-dimensional and two-dimensional displacement experiments are designed using the experimental similarity criteria according to the actual reservoir parameters. Several experimental schemes are designed, fluid physical properties, interlayer distribution, and development mode according to the actual reservoir physical properties. Through the visualization of experimental equipment, the bottom water reservoir is visually stimulated. The displacement and sweep law of natural water drive and artificial water injection in bottom water reservoir with or without an interlayer, different viscosity, and different well spacing is analyzed. The following conclusions are obtained: (1) For reservoirs with a viscosity of $150 \mathrm{cp}$. The recovery factor after water injection is slightly higher than before water injection. However, the recovery factor is lower than that without injection production. The reason is that the increment of injection conversion is limited to reduce one production well after injection conversion. (2) For reservoirs with a viscosity of $30 \mathrm{cp}$. The recovery factor after injection is $39.8 \%$, which is slightly higher than $38.9 \%$ without injection. (3) For reservoirs with a viscosity of $150 \mathrm{cp}$. In the case of the interlayer. The recovery factor after injection is $30.7 \%$, which is significantly higher than $24.8 \%$ without injection. (4) After the well spacing of the low-viscosity reservoir is reduced, the recovery factor reaches $46.1 \%$, which is higher than $38.9 \%$ of the non-infill scheme. After the infill well in a low-viscosity reservoir is transferred to injection, the recovery factor is $45.6 \%$, which has little change compared with non-injection, and most of the cumulative production fluid is water. The feasibility and effect of water flooding in a strong bottom water reservoir are demonstrated. This study provides the basis for the proposal of production well injection conversion and the adjustment of production parameters in the highest water cut stage of a big bottom water reservoir.
\end{abstract}

Keywords Strong bottom water reservoir $\cdot$ Experiment $\cdot$ Water flooding $\cdot$ Physical model $\cdot$ Feasibility

\section{Introduction}

A bottom water reservoir is a kind of common reservoir type, a reservoir with 0 oil-bearing areas. Bottom water is a vital driving energy source for this kind of reservoir, but at the same time, it would bring a series of problems to reservoir development. The bottom water reservoir is prevalent at home and abroad, widely distributed in many oil-producing areas globally. In fact, in addition to the original bottom

Jie Tan

4687610@qq.com

1 Tianjin Branch of CNOOC Ltd., Tianjin, China water reservoir, the transition zone of the edge water reservoir also has the property of the bottom water reservoir, so some theories of developing bottom water reservoir are also applicable to the development of crude oil in the transition zone of edge water reservoir. At the same time, the edge water reservoir would evolve into a secondary bottom water reservoir in the later stage of high water cut development, which can also be guided by the development theory of the bottom water reservoir. Therefore, the study of bottom water reservoirs has a significant reference value for developing many different types of reservoirs (Escobar and Djebbar 2002; Cheng et al. 2012; An et al. 2008).

For the bottom water reservoir, carbonate reservoir is studied earlier, and the typical one is the carbonate bottom 
water reservoir in Renqiu oilfield. Since the reservoir was produced, it has experienced three stages: elastic drive, elastic hydraulic drive, and artificial hydraulic drive. Affected by bottom water, the oil recovery period is three years, and the recovery rate is $7.2 \%$. According to the type of carbonate reservoir space and the fluid's flow, pattern, and movement characteristics, the Wumishan formation reservoir in Renqiu oilfield comprises fracture and rock block systems with dual pore structure characteristics. Due to the existence of a fracture system, the water breakthrough speed of the bottom water reservoir in the Wumishan formation of Renqiu oilfield is quite fast. Through the core displacement experiments of typical wells, it is found that the recovery ratio of each stage in Renqiu oilfield varies considerably: The recovery ratio of fractures and large cores in the high water cut stage accounts for more than $75 \%$ of the total recovery ratio, and the recovery ratio of water-free and low water cut stage is less than $10 \%$, while the recovery ratio of small-diameter cores in water-free and low water cut stage accounts for more than half of the total recovery ratio, and the recovery ratio of high water cut stage is less than $40 \%$. It is consistent with the cognition of low recovery in low water cut stage of bottom water reservoir (Henley et al. 1961; Ragunathan et al. 2021; Ogbeiwi et al. 2018; Checng et al. 1994; Alizadeh and Salek 2021; Islam and Yin 1999; Puchyr 1991).

Experts have carried out many theoretical and experimental studies to restrain bottom water coning and improve the development effect of horizontal wells. French engineers first put forward the concept of "critical production," which provides ideas for the follow-up study of efficient exploitation of bottom water reservoirs. Then, Henley, Owens, and Craig studied the influence of flow rate, capillary force, perforation degree, and well spacing on bottom water reservoir production by the experimental method and proved that the impermeable separator has an excellent effect on inhibiting bottom water coning (Zheng et al. 1996; Archer and Yildiz 2001).

When Zhou Yanxia and others studied the edge and bottom water reservoir in Hongnan oilfield through indoor physical simulation experiments, they thought depletion development had a low recovery for the edge and bottom water reservoir. When the water injection development was adopted, the appropriate increase of injection pressure could improve the recovery. In addition, it is also found that the implementation of bottom water plugging can improve the waterflooding development effect. Implementing foam huff and puff can further enhance the recovery factor, but the increase is slight. Other decisions can be made according to the actual production plan, capital input, and reservoir and fluid properties (Zheng et al. 2015; Le 2013; Ning et al. 2004).

According to the research of Zhang Jilei and others, the continental sandstone bottom water reservoir, to the ultra-high water cut stage, generally uses the production well injection method to improve the displacement efficiency. However, through the reservoir numerical simulation and field practice, it is found that the displacement effect of the directional well is poor, only the flowing pressure rises slowly, and the injected water mainly shows the role of supplementing energy. The swept volume of injected water in the bottom water reservoir is analyzed according to the dynamic response characteristics, combined with the streamline simulation method. It is concluded that most of the injected water mainly flows to the bottom water area, which is used to supplement the bottom water energy, and then the injection water is produced through the production well, resulting in the invalid circulation of injected water, and the oil displacement effect is not apparent. Even the swept volume of injected water in production wells is much smaller than indirect injection wells. The reason is that the injected water is affected by the upbeat rhythm and a large amount of liquid scouring after the directional well is converted to injection, and the injected water forms a "U" tube-type invalid cycle. Therefore, for the bottom water sandstone reservoir, the displacement efficiency of water injection wells deployed at the stage of oilfield production is better than that of later production wells (Jiang 2013; Zhang et al. 2020).

Huang Chunjin et al. discovered the development process of the Jurassic bottom water reservoir in the yuan435 area of Yuancheng oilfield that with the deepening of the development degree, especially in the middle and high water cut development stage, the perfection degree of the formation has changed. The contradiction of the oil layer plane, interlayer, and inner layer is more prominent, which leads to the increase of water cut, the increase of productivity decline, and the decrease of pressure maintenance level. After the bottom water coning, the treatment measures are single, complex, and low success rate. After waterflooding development of the oilfield, the formation energy is effectively replenished, the overall development situation is improved, and the production decline and water cut rise are slowed down. At the same time, the injection production ratio is optimized, the reverse nine-point pattern is adopted, the water injection wells are deployed in the middle of the sand body as far as possible, and the ratio of oil and water wells is $3: 1$. The injection production ratio of the block is $0.6-0.8$, and the geological injection allocation of the single well is $10 \mathrm{~m}^{3} / \mathrm{d}$. A total of 6 injection wells were transferred, using mild water injection, with an injection volume of $60 \mathrm{~m}^{3}$. After reasonable water injection development, the annual oil production level keeps a steady rising trend. The total decline rate drops significantly, from 18.57 to 11.11 , which is in a continuous decline state, effectively curbing the production decline and improving the development speed of the yuan435 area (Wang 2015). 
After water injection development in yuan435 District, the formation energy is tamped, and the development effect is good. The average bottom hole flowing pressure of yuan 435 area is $7.4 \mathrm{MPa}$ at the initial stage of production, which is $6.8 \mathrm{MPa}$ before water injection and $0.6 \mathrm{MPa}$ lower than that at the initial stage of production. At present, the average bottom hole flowing pressure is $7.7 \mathrm{MPa}$, which is higher than that before water injection. In different development stages, the bottom pressure distribution chart shows that the bottom hole flow pressure is mainly distributed in 4-10 MPa. Therefore, the bottom flow pressure of the well is relatively average in the initial stage of production, the difference between wells is slight, and the formation energy distribution is stable. However, with the continuous exploitation of oil fields, the bottom hole pressure has decreased before waterflooding development due to the heterogeneity of formation, and the difference of bottom hole pressure distribution is further expanded. After waterflooding, the average bottom hole pressure has risen, but the heterogeneity of formation is further highlighted, and the difference of bottom pressure distribution is expanded again. Therefore, it is urgent to optimize injection and production parameters reasonably and strictly control the push speed of the side and bottom water while maintaining the formation energy (Zhao 2018).

Longming et al. have found that the bottom water reservoir can maintain the formation pressure and play a good oil displacement effect by water injection in the process of studying the refined water injection in the bottom water reservoir of Bohai Q oilfield. In the past, the research on waterflooding development of bottom water reservoirs mainly focused on maintaining formation pressure by waterflooding but little on waterflooding. Therefore, the waterflooding development model of the bottom water reservoir can be divided into two types: the bell-type model mainly for oil displacement and the funnel-type model mainly for pressure maintaining (Long et al. 2017).
From the research status, the commonly used methods to tap the potential of the remaining oil in the base reservoir include well pattern infilling, extensive pump extraction. The methods to improve oil displacement efficiency in the ultrahigh water cut stage include optimizing injection production mode, chemical water shutoff, water gas alternate injection, etc. Water injection is mainly used to maintain formation pressure in the bottom water reservoir, but there is little research on water injection displacement to study the effect of water flooding in the bottom water reservoir. The indoor quasi-three-dimensional and two-dimensional displacement experiments are designed using the experimental similarity criterion according to the actual reservoir parameters. According to the physical properties of the actual reservoir, fluid physical properties, interlayer distribution, and development mode, several groups of experimental schemes are designed. The experimental visual equipment is used to intuitively simulate the bottom water reservoir and analyze the reservoir displacement and sweep law in the stage of natural water drive and artificial water injection in the bottom water reservoir with or without an interlayer, different viscosity, and different well spacing. The feasibility of water injection development of a strong bottom water reservoir is demonstrated. It provides a basis for the transfer of production wells to injection in the highest water cut stage of the strong bottom water reservoir and adjusting production parameters.

\section{Determination of basic parameters of physical simulation experiment}

The similarity number is obtained by using the similarity criterion. Calculate and select the similarity number needed for the experimental design. Thus, the model parameters of the experimental design are determined, and the experimental model design and experimental optimization are carried out. Combined with the actual reservoir parameters, the model parameters are obtained (Table 1).
Table 1 Comparison table of original parameters and experimental model parameters

\begin{tabular}{llll}
\hline Parameters & Original reservoir & $\begin{array}{l}\text { Quasi-3D physical } \\
\text { model }\end{array}$ & 2D section \\
\hline Reservoir length (m) & 1200 & 1 & 0.5 \\
Reservoir width (m) & 1500 & 0.3 & 0.05 \\
Reservoir thickness (m) & 15 & 0.15 & 0.05 \\
Well spacing (m) & 350 & 0.35 & 0.15 \\
Porosity (\%) & 30 & 30 & 30 \\
Average permeability $\left(10^{-3}{\left.\mu \mathrm{m}^{2}\right)}_{\text {Well diameter }(\mathrm{m})}\right.$ & 2000 & 2000 & 2000 \\
Viscosity of crude oil $(\mathrm{cp})$ & 0.138 & 0.03 & 0.03 \\
Crude oil density $\left(\mathrm{g} / \mathrm{cm}^{3}\right)$ & 150 & 150 & $150 / 30$ \\
Water injection rate $(\mathrm{ml} / \mathrm{min})$ & 970 & 970 & 890 \\
\hline
\end{tabular}




\section{Physical simulation experiment design of reservoir development with big bottom water}

According to the similarity number obtained by the similarity criterion, the model's size is determined according to the characteristics of the thin reservoir in the target oilfield. Transparent plexiglass was selected as the model boundary, and acrylic glass adhesive was used for cementation. Different mesh quartz sand and epoxy resin are used to cement the filling medium, making the surface wettability weakly lipophilic and ensuring the visualization of the model.

\section{Model making}

1. The modified acrylic adhesive (acrylic glass adhesive) was used to bond the PMMA board;

2. The epoxy resin and curing agent were mixed in the ratio of $1: 1$ and mixed with quartz sand according to a specific mass fraction. Then the prepared matrix was poured into the model and compacted, and the surface was treated evenly and cured at room temperature for $4 \mathrm{~h}$;

3. The electric drill is used to drill the well located at the injection production well, connect the pipelines, and completely seal the model.

\section{Three-dimensional large-scale model}

According to the similarity number obtained by the similarity criterion and the characteristics of thin oil layers in the target oilfield, the size of the three-dimensional largescale physical simulation experiment model is determined as $100 \mathrm{~cm} \times 30 \mathrm{~cm} \times 30 \mathrm{~cm}$ (length $100 \mathrm{~cm}$, width $30 \mathrm{~cm}$, height $30 \mathrm{~cm}$ ). The transparent, toughened glass was selected as the upper cover of the model, and the outer part was reinforced with grid-shaped cast iron and rotated for $90^{\circ}$. Make the glass plate face the front to ensure the visualization of the model (Fig. 1). The filling medium of the model is divided into upper and lower layers. The upper layer is filled $15 \mathrm{~cm}$ with quartz sand and Sudan three dyed crude oil to simulate the oil layer of the reservoir, and the lower layer is filled $15 \mathrm{~cm}$ with the same quartz sand and black ink to simulate the water layer the reservoir.

\section{Profile analysis model}

To further analyze the displacement characteristics of bottom water reservoir waterflooding development, three sets of profile analysis models are made: The model is spliced with a transparent glass plate, and the model size is
$50 \mathrm{~cm} \times 15 \mathrm{~cm} \times 5 \mathrm{~cm}$ (length $50 \mathrm{~cm}$, width $15 \mathrm{~cm}$, height $5 \mathrm{~cm}$ ), and the model can be seen from six sides. The filling medium of the model is divided into upper and lower layers. The upper layer is filled with $8 \mathrm{~cm}$ of quartz sand and Sudan three dyed crude oil to simulate the oil layer of the reservoir. The lower layer is filled with $5 \mathrm{~cm}$ of the same quartz sand and black ink to simulate the water layer of the reservoir. Finally, a permeable partition is added at the bottom of the model to form a closed space to produce stable bottom water (Fig. 2).

\section{Experimental preparation}

Viscosity temperature test:

1. First, a certain amount of engine oil would be obtained;

2. The viscosity-temperature curve of engine oil was measured by rheometer (Fig. 3);

3. Oil and kerosene are proportioned according to 10:2 and 10:3 to produce crude oil with target reservoir viscosity of $150 \mathrm{cp}$ and $30 \mathrm{cp}$ (Because the color of crude oil in the target reservoir is dark and inconvenient to observe, engine oil is selected to replace crude oil. At the same time, the viscosity of crude oil in the target reservoir is achieved by mixing with kerosene. The experimental oil was dyed red with Sudan red to make the experiment easy to observe.);

4. Rheometer was used to test the viscosity-temperature curves of different proportion combinations, and the viscosity of different proportion combinations at room temperature was recorded.

\section{Steps of making 2D section model}

1. The transparent plexiglass was cut and assembled into three-dimensional models of $50 \mathrm{~cm}$ in length, $15 \mathrm{~cm}$ in width, and $3 \mathrm{~cm}$ in height;

2. Three horizontal wells $\mathrm{H} 1, \mathrm{H} 2$, and $\mathrm{H} 3$ with horizontal section length of $2 \mathrm{~cm}$ were produced; Four horizontal wells were made at the bottom of the model to simulate that the bottom water was evenly installed at the bottom of the model;

3. A 50-cm-long and 3-cm-wide partition board is added $2 \mathrm{~cm}$ away from the model's bottom. The partition board is perforated evenly, and a layer of yarn mesh is added above it for sand control, as shown in Fig. 4;

4. The "oil sand" with a viscosity of $150 \mathrm{cp} / 30 \mathrm{cp}$ was made by mixing engine oil and kerosene at the ratio of 10:2/10:3. Mix the same quartz sand and diluted ink evenly to form "water sand";

5. Fill $5 \mathrm{~cm}$ "water sand" above the model "pure water area" to simulate "water layer," and fill $5 \mathrm{~cm}$ "oil sand" above it to simulate "oil layer"; 
Fig. 1 3D large-scale physical model
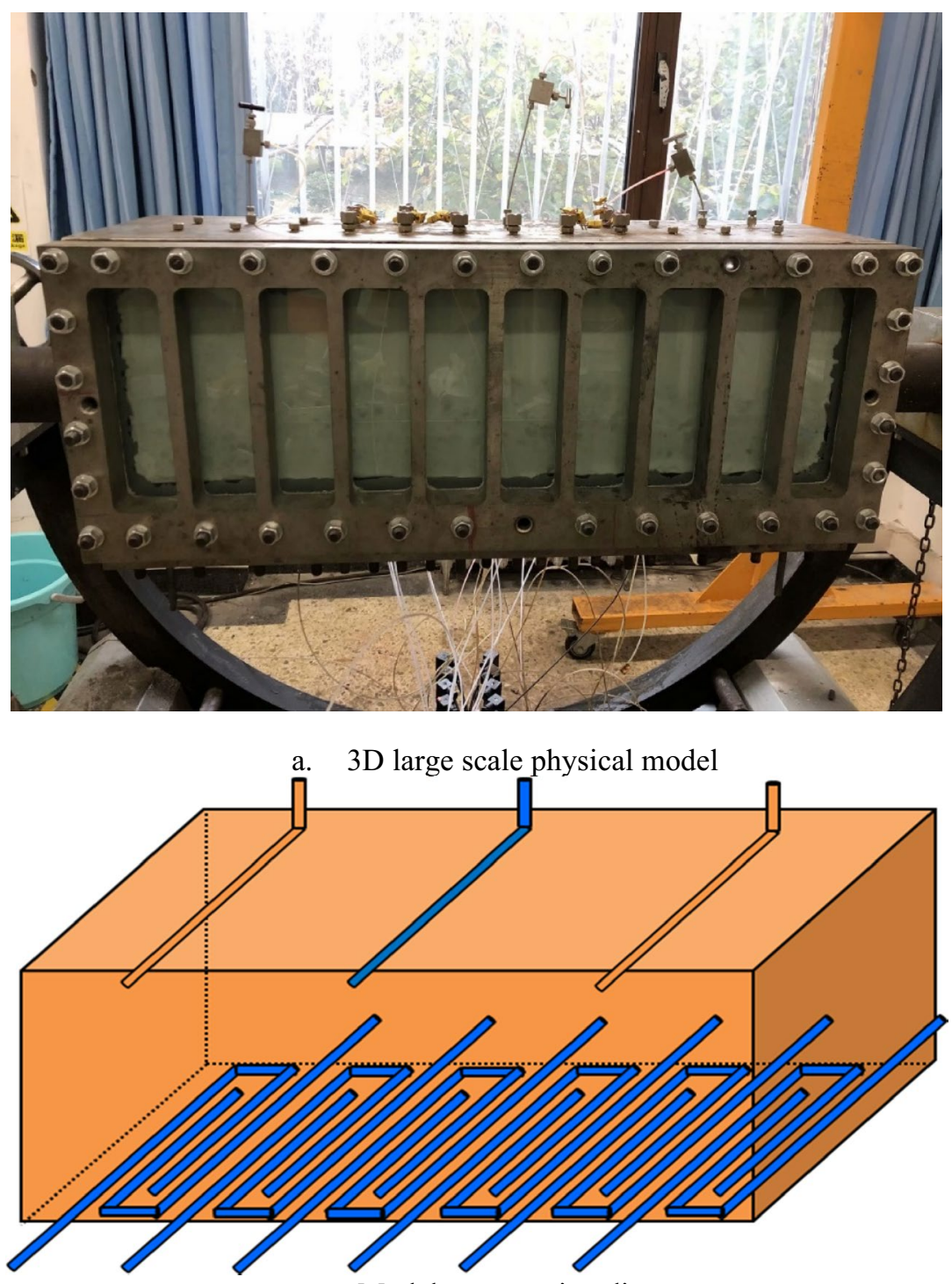

a. Model construction diagram

6. When the sandwich model is filled with "oil sand," a $0.3-\mathrm{cm}$-thick $45-\mathrm{cm}$-long plexiglass plate is horizontally embedded close to the left side of the model and its front and rear walls to simulate the sandwich, as shown in Fig. 5;

7. The modified acrylic adhesive was used to reinforce and seal the transparent PMMA, and the visualization of model 6 was ensured.

\section{Experimental conditions and procedures}

\section{Experimental condition}

1. Model size: $50 \mathrm{~cm} \times 5 \mathrm{~cm} \times 15 \mathrm{~cm}$;
2. Experimental water: formation water, total salinity $3856 \mathrm{mg} / \mathrm{L}$.

3. Oil and kerosene are proportioned according to 10:2 And 10:3 to produce crude oil with target reservoir viscosity of $150 \mathrm{cp}$ and $30 \mathrm{cp}$. (The experimental oil was dyed red with Sudan red to make the experiment easy to observe).

4. The experimental temperature was $25^{\circ} \mathrm{C}$.

\section{Experimental device}

The experimental visualization device comprises an advection pump, intermediate vessel, six-way valve, high-precision pressure gauge, oil-water separator, and image acquisition system. Add blue ink into water, dye it blue, and use Sudan III to dye it red, making the practical effect more obvious (Fig. 6). 


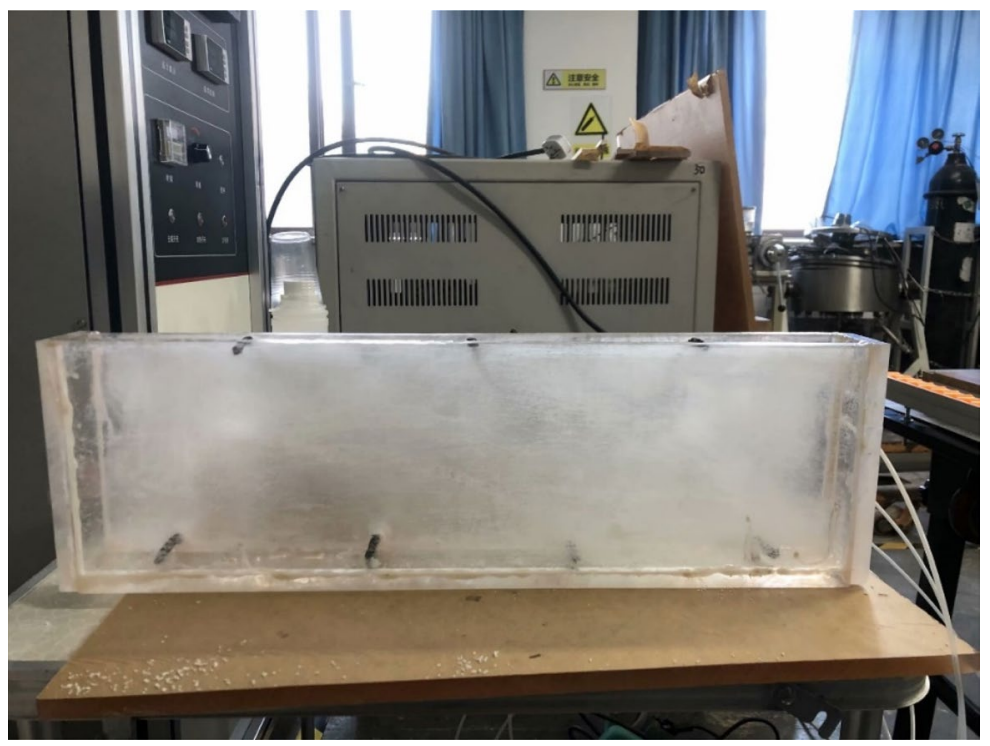

a. Front view of the section analysis model

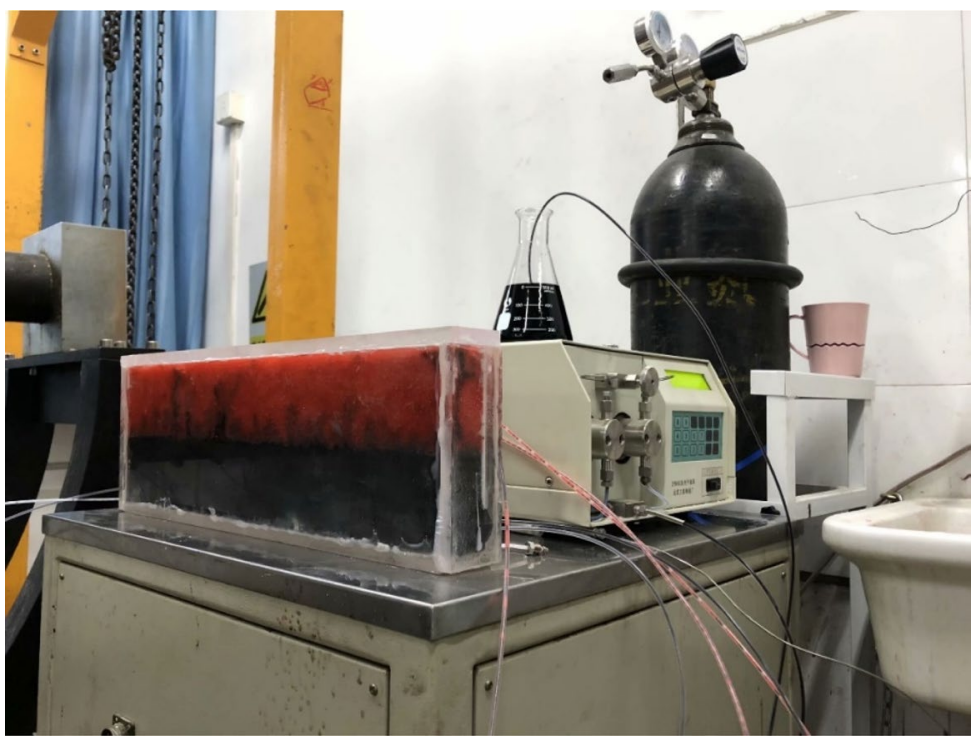

b. Side view of the section analysis model

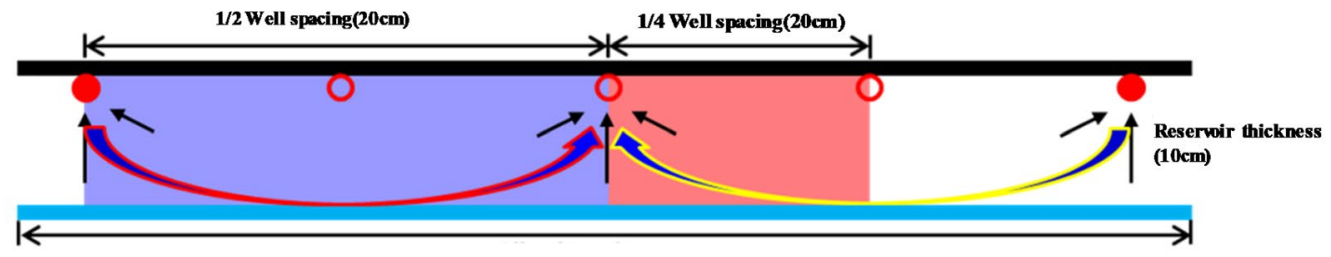

c. Visual model diagram

Fig. 2 Physical model of profile analysis

\section{Experimental steps}

1. Add the dyed kerosene into the intermediate container and connect the pipeline according to the experimental flowchart;
2. The dry weight of the model was weighed, the saturated water was evacuated, and then the porosity was measured;

3. Irreducible water is formed by oil drive water, and saturated oil quantity is recorded; 


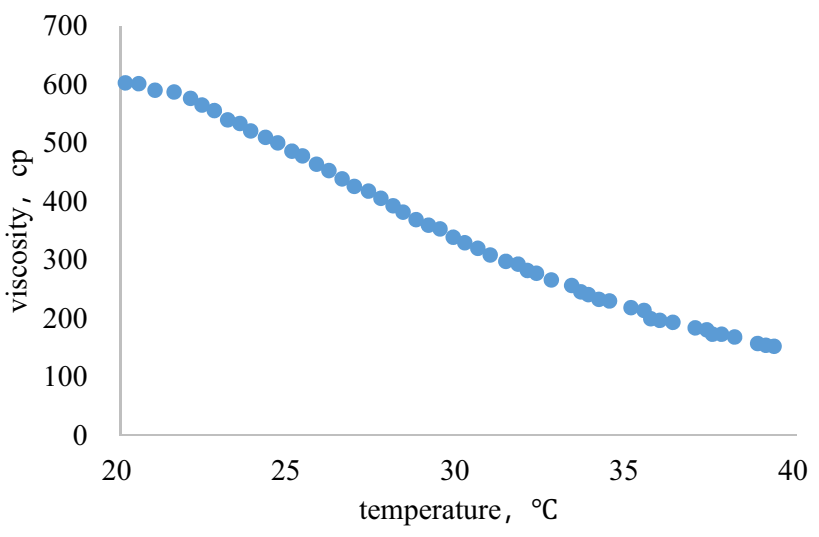

Fig. 3 Viscosity-temperature curve of original oil

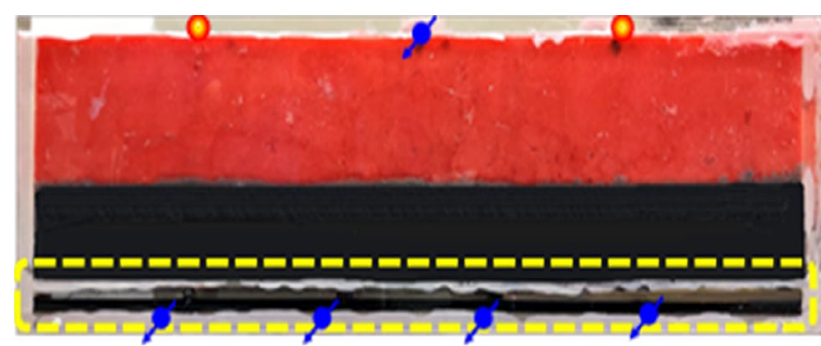

Fig. 4 Model diagram of pure water area

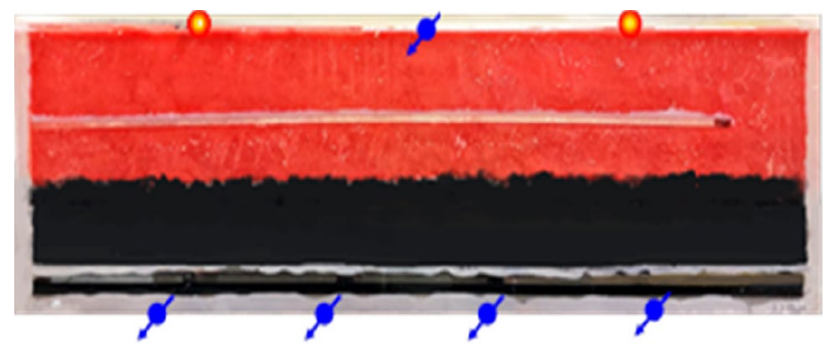

Fig. 5 2D section model with partition

4. Change the valve, set the injection speed of the advection pump, and adjust the position of the camera;

5. Turn on the running switch of the advection pump and start the test. The camera recorded the injection pressure, cumulative oil production, cumulative injection volume, and water breakthrough time, and the camera recorded the oil-water flow process in the model. The experiment was stopped until the water cut was $98 \%$;

6. Replace the model and repeat steps (1)-(5).

\section{Analysis of experimental results}

The following solutions can be obtained through experiments: (1) For reservoirs with a viscosity of $150 \mathrm{cp}$. The recovery factor after water injection is slightly higher than before water injection. However, the recovery factor is lower than that without injection production. The reason is that the increment of injection conversion is limited to reduce one production well after injection conversion. (2) For reservoirs with a viscosity of $30 \mathrm{cp}$. The recovery factor after injection is $39.8 \%$, which is slightly higher than $38.9 \%$ without injection. (3) For reservoirs with a viscosity of $150 \mathrm{cp}$. In the case of the interlayer. The recovery factor after injection is $30.7 \%$, which is significantly higher than $24.8 \%$ without injection. (4) After the well spacing of the low-viscosity reservoir is reduced, the recovery factor reaches $46.1 \%$, which is higher than $38.9 \%$ of the non-infill scheme. After the infill well in a low-viscosity reservoir is transferred to injection, the recovery factor is $45.6 \%$, which has little change compared with non-injection, and most of the cumulative production fluid is water.

\section{Results analysis of 3D large-scale model}

Because the model is large, the sand is difficult to be compacted, and the high permeability area is easy to appear. As a result, the water infiltrates between the glass and the sand, which affects the visual surface observation. However, the degree of sand compaction in the 3D large-scale model is similar to the actual reservoir, and the fluid flow resistance is also similar. Therefore, to better understand the oil displacement mechanism of natural water flooding and water flooding in the bottom water reservoir, the sand body in the model is cut layer by layer, and the fluid distribution on the cut section can reflect the fluid distribution of the actual reservoir. For example, the following would analyze the $1 / 3,1 / 2,2 / 3$, and $5 / 6$ sections of the internal section of the model (Fig. 7):

The results of the section $10 \mathrm{~cm}(1 / 4)$ away from the model's frontal plane are shown in Fig. 8.

1. Well H1: There is a prominent water cone nearby, and the volume is large, but no apparent lateral displacement of water injection well is found;

2. H3 well: there is a specific water cone with a small volume, and it is found that there is a certain lateral displacement of water injection well on the left side;

3. Well H2 (reinjection well): there is no water cone in this profile before reinjection, and there is certain lateral displacement for well $\mathrm{H} 3$ after reinjection. 


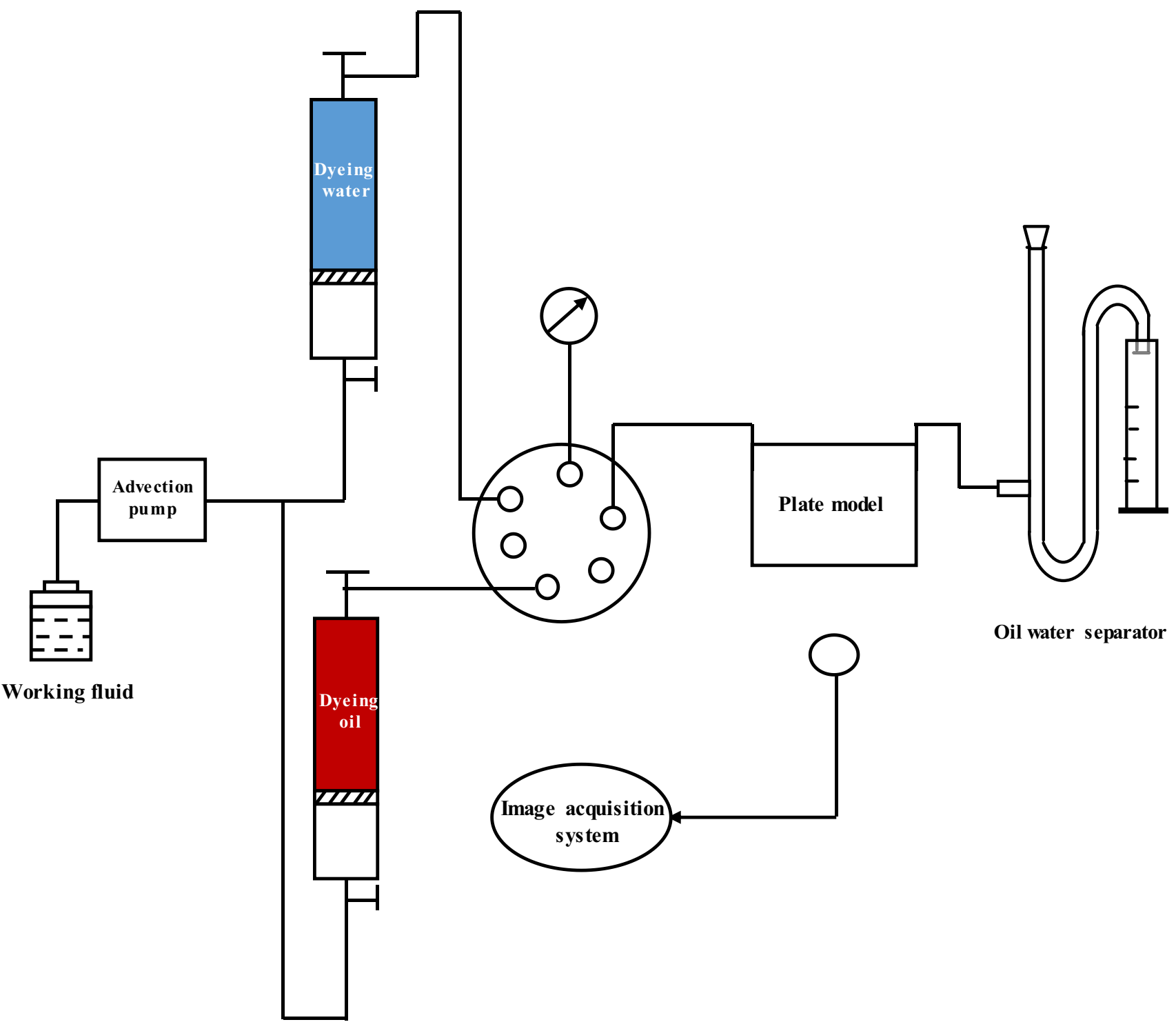

Fig. 6 Flowchart of visualization experiment device

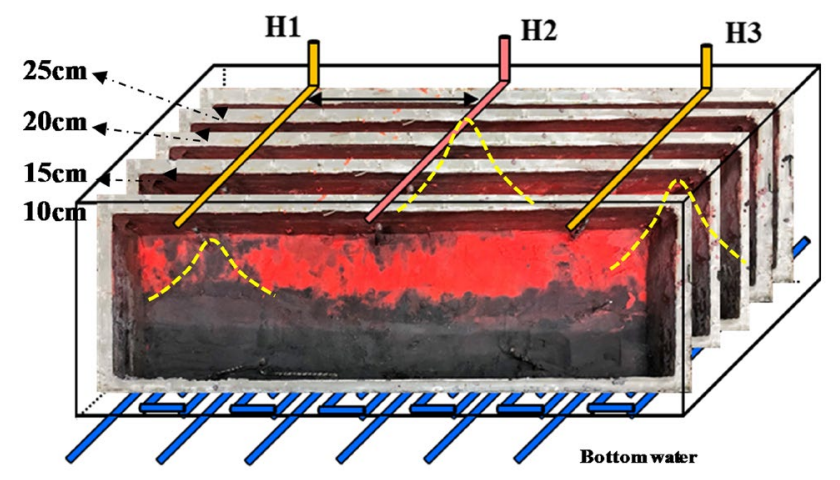

Fig. 7 Schematic diagram of section selection

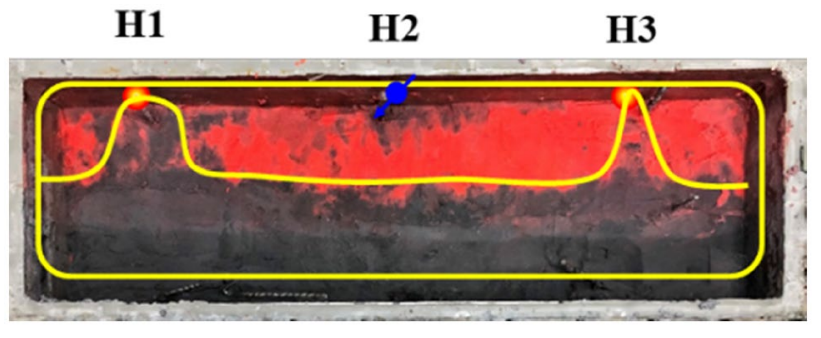

Fig. 8 Profile of $1 / 4$ part of the model

$15 \mathrm{~cm}(1 / 2)$ away from the model plane belongs to the middle of the model, the sand body is compact, and there is no high permeability channel. The porosity and permeability parameters are closer to the actual results 


\section{H1}

H2

H3

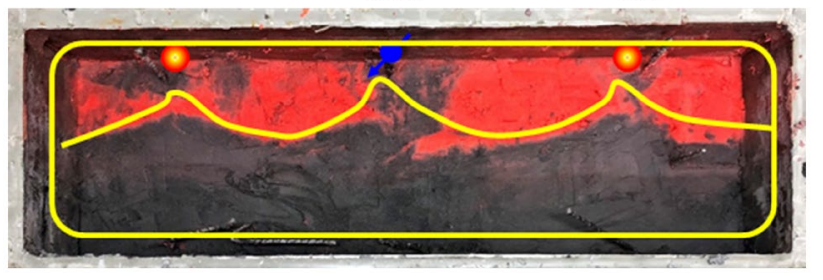

Fig. 9 Profile of model 1/2

H1

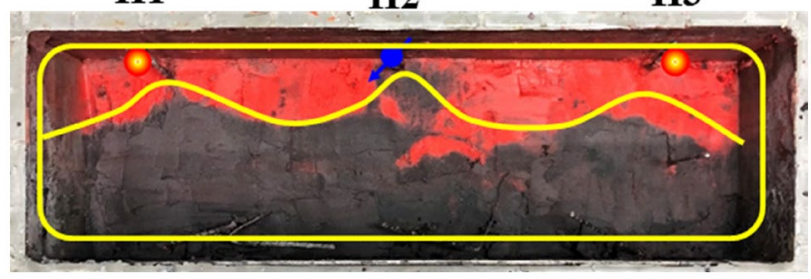

Fig. 10 Section of $3 / 4$ of the model

calculated by the similarity criterion, and the distribution of porosity and permeability is more uniform, which can truly reflect the actual situation of reservoir seepage. The profile results are shown in Fig. 9

1. Well H1: the water cone decreases obviously, and no apparent lateral displacement of water injection well is found;

2. H3 well: there is a specific water cone with large volume, and a certain lateral displacement of water injection well is found;

3. Well H2 (reinjection well): there is a large water cone in this profile before reinjection, and there is a certain lateral displacement for well $\mathrm{H} 3$ after reinjection; affected by the artificial water injection in the later stage, the water saturation in the $\mathrm{H} 2$ control area of intermediate injection well is higher than that of production wells on both sides.

The profile results at $20 \mathrm{~cm}(3 / 4)$ away from the model's frontal plane are shown in Fig. 10.

1. Well H1: Water cone appears, but it is not apparent, and no apparent lateral displacement of water injection well is found;

2. H3 well: No water cone, no lateral displacement;

3. Well H2 (reinjection well): The water cone of this profile is large before reinjection, and there is no lateral displacement for well $\mathrm{H} 3$ after reinjection.

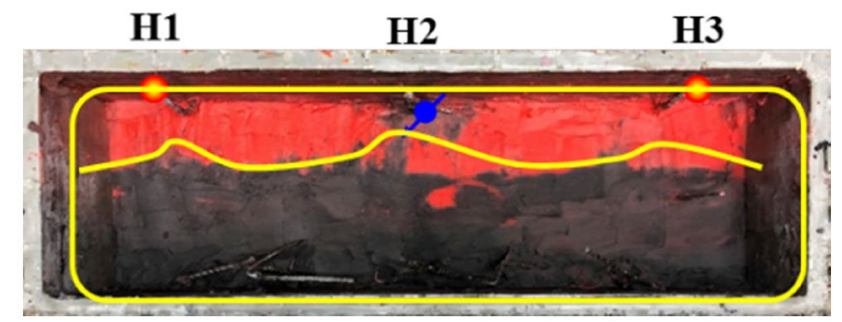

Fig. 11 The section at $4 / 4$ of the model

Table 2 Water breakthrough position and water injection effect position of horizontal well

\begin{tabular}{lll}
\hline Well number & $\begin{array}{l}\text { Water breakthrough position } \\
\text { of bottom water }\end{array}$ & $\begin{array}{l}\text { Influential posi- } \\
\text { tion of water } \\
\text { injection }\end{array}$ \\
\hline $\mathrm{H} 1$ & Nothing \\
$\mathrm{H} 2$ & $1 / 2,2 / 3$ & \\
$\mathrm{H} 3$ & $1 / 3,2 / 3,5 / 6$ & $1 / 3,1 / 2$ \\
\hline
\end{tabular}

The results of the section $25 \mathrm{~cm} \mathrm{(4/4)} \mathrm{away} \mathrm{from} \mathrm{the}$ model's frontal plane are shown in Fig. 11.

1. H1 well: There is no noticeable water cone, and the lateral displacement effect of the $\mathrm{H} 2$ well is fragile;

2. H3 well: No water cone, no lateral displacement of water injection well is found;

3. Well H2 (reinjection well): The water cone of this profile is small before reinjection, and the lateral displacement of well $\mathrm{H} 3$ is not apparent after reinjection.

The following conclusions can be drawn from the profile oil-water distribution map at different positions of the 3D large-scale model.

1. The water breakthrough characteristics of horizontal wells in heavy oil reservoirs are as follows: From the point of water, it gradually becomes a water cone and finally forms a ridge of water (bottom water breakthrough along wellbore is not wholly upward, Table 2);

2. Sweep characteristics of injection wells: The water injection expands outside the water cone and directly enters the bottom water when it reaches the water cone. The lateral displacement of water injection is selective, which is mainly concentrated in the place where no water cone is formed;

3. The water cone formed by well $\mathrm{H} 1$ is higher than that formed by well $\mathrm{H} 3$ and that formed by well $\mathrm{H} 2$;

4. Due to the influence of bottom water coning, the degree of water flooding near horizontal wells is high, water flooding between wells is low, and a large amount of 
remaining oil is distributed, which has the potential infilling.

The recovery factor after water injection is $24.3 \%$, which is slightly higher than that before water injection. However, the recovery factor of $24.9 \%$ is lower than that without injection production. The reason is that the increment of injection conversion is limited to reduce one production well after injection conversion (Fig. 12).

\section{Analysis of 2D profile model results}

According to the results of a three-dimensional large-scale physical simulation experiment, the water breakthrough characteristics of horizontal wells in the bottom water reservoir are cones and not an overall rising ridge. To further analyze the profile characteristics of water breakthrough in the bottom water reservoir, according to the results of quasi-three-dimensional physical simulation experiment, three groups of experiments are designed according to the difference of crude oil viscosity and the presence or absence of interlayer.

Experimental scheme 1 (viscosity is $150 \mathrm{cp}$, no interlayer, see Fig. 13).

\section{Before reinjection}

- Well H1: Water coning occurred, and lateral displacement occurred after injection;

- H3 well: Water cone is prominent, but lateral displacement is weak after injection;

- Well H2 (reinjection well): The coning of reinjection is obvious, and the change is small after reinjection.

- Water cones of different sizes appear in all three wells, and the remaining oil between wells is apparent.

After reinjection
- Well H1: Water coning occurred, and lateral displacement occurred after injection;

- Well H3: Water cone is prominent, but lateral displacement is weak after injection;

- Well H2 (reinjection well): The coning of reinjection is obvious, and the change is small after reinjection.

After water injection (without considering liquid extraction), the recovery factor is $27.5 \%$, slightly higher than before water injection. However, $28.7 \%$ is lower than without injection production. The reason is that the increment of injection conversion is limited to reduce one production well after injection conversion.

Experimental scheme 2 (viscosity is $30 \mathrm{cp}$, without an interlayer, see Fig. 14).

\section{Before reinjection}

- Well H1: The radius of the water cone is large, and the bottom water wave and its range are large;

- Well H3: The water cone is prominent, and the degree of water washing inside the water cone is very high, and the area of bottom water not affected is tiny;

- Well H2 (reinjection well): The water cone is prominent, and the internal water washing degree of the water cone is lower than that of well $\mathrm{H} 1$ and $\mathrm{H} 3$.

- Due to the low viscosity of crude oil, the water cut increases rapidly after well opening, the reservoir seepage resistance is small, the water wave is relatively uniform, the water breakthrough is fast after well opening, and the remaining oil area is small in the later stage of production;

\section{After reinjection}

- Well H1: The water cut of well H1 increased rapidly before injection, decreased after injection, and then increased slowly;
Fig. 12 Recovery comparison of 3D model

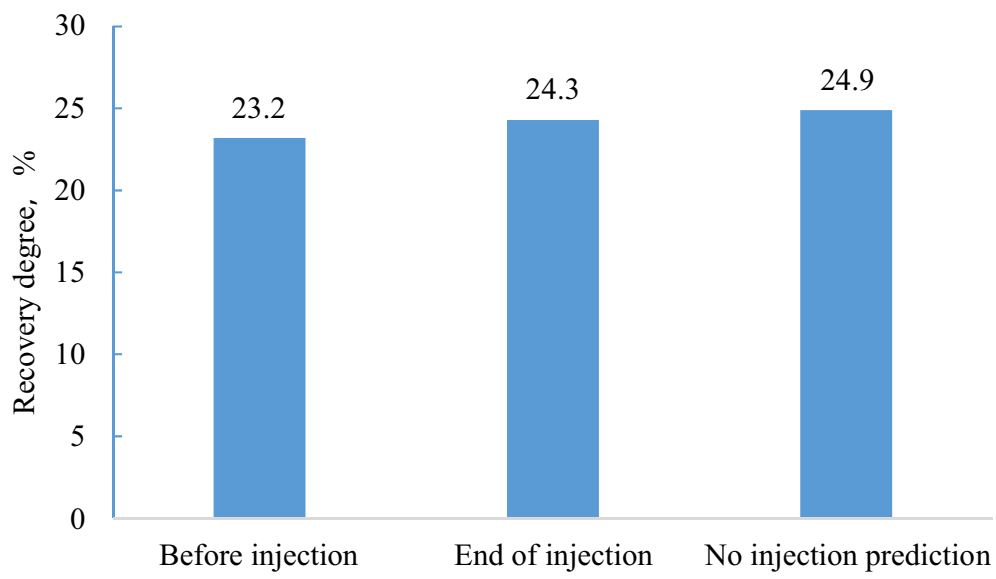


Fig. 13 Experimental scheme 1 analysis of experimental results

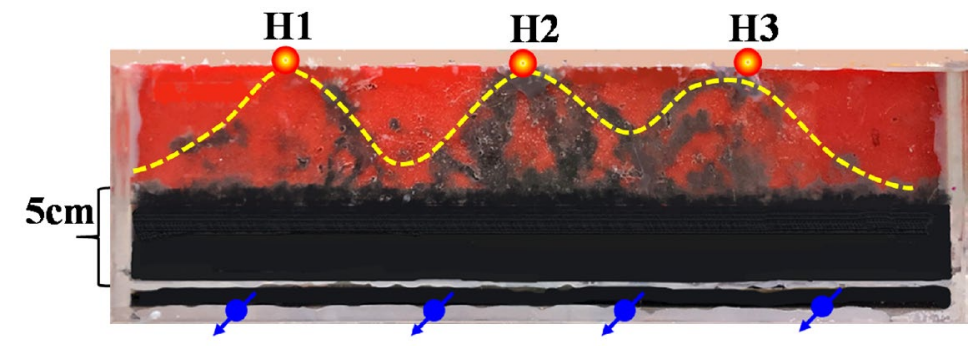

a. oil saturation distribution before injection in scheme 1 Reservoir

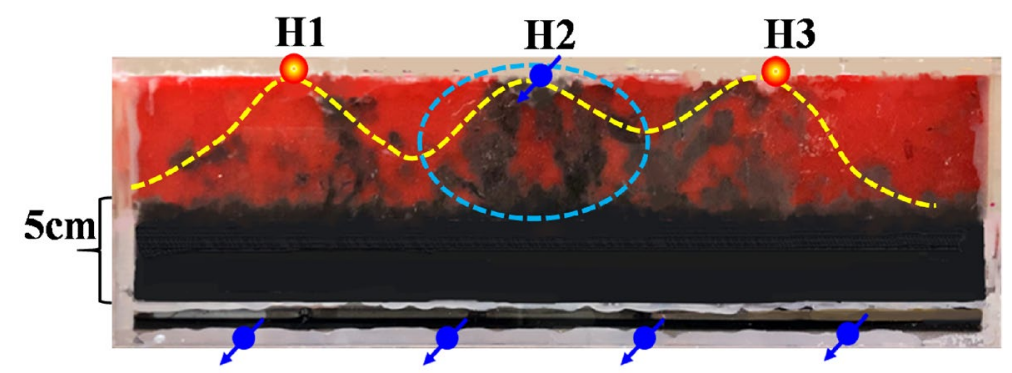

b. oil saturation distribution after injection in scheme 1 Reservoir

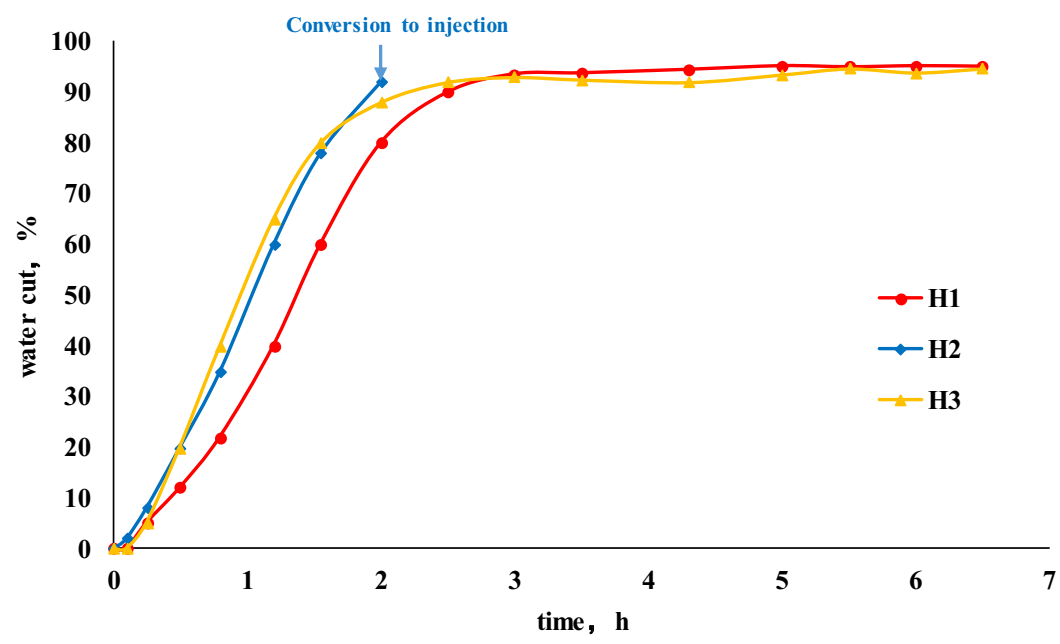

c. water cut change of three horizontal wells in scheme 1 Reservoir

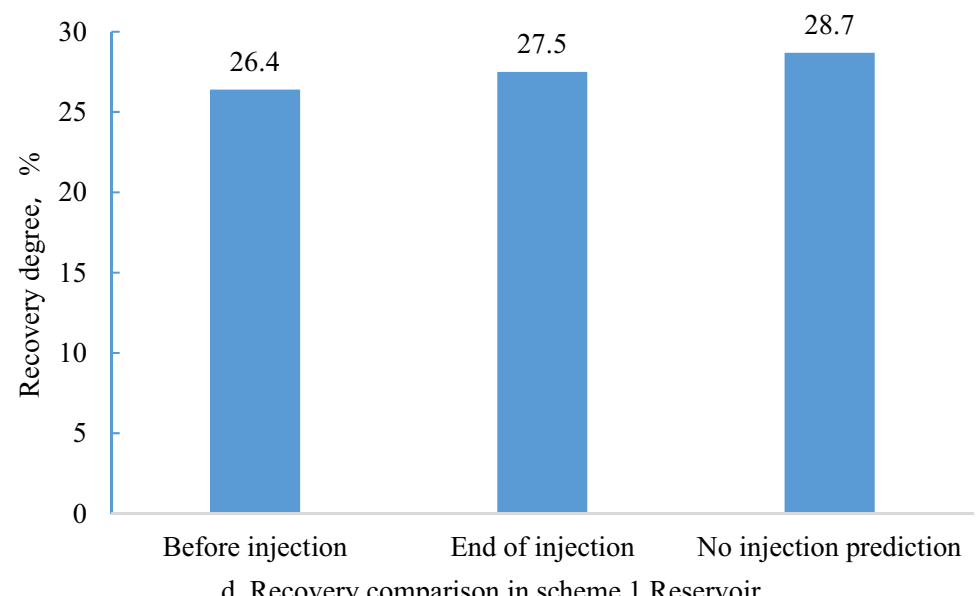

d. Recovery comparison in scheme 1 Reservoir 
Fig. 14 Experimental scheme 2 analysis of experimental results

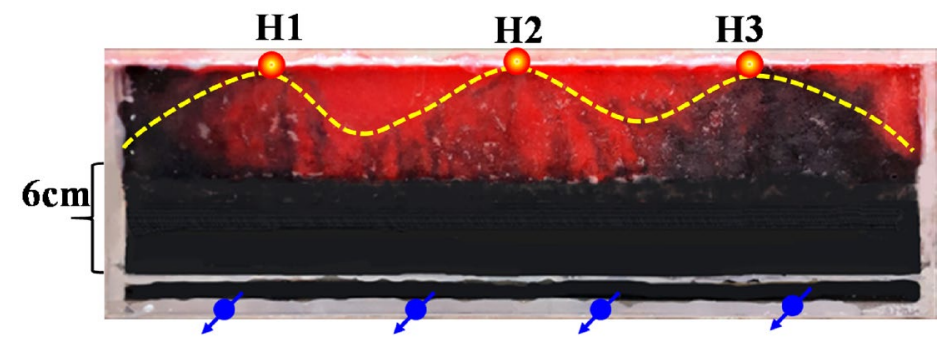

a. Oil saturation distribution before injection in scheme 2 reservoir

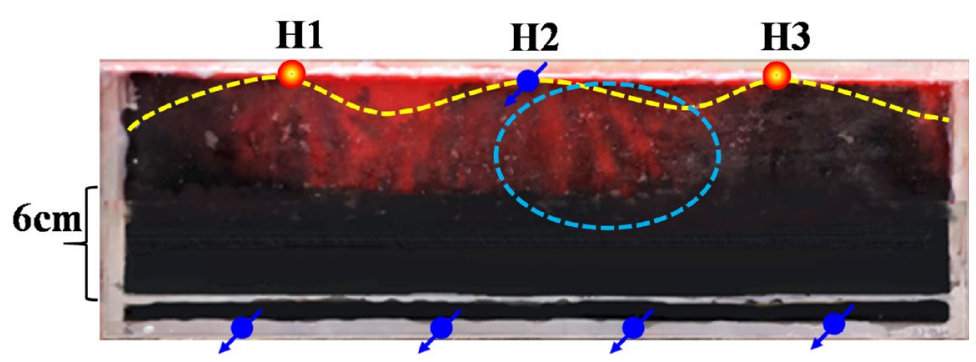

b. Oil saturation distribution map of scheme 2 reservoir after injection

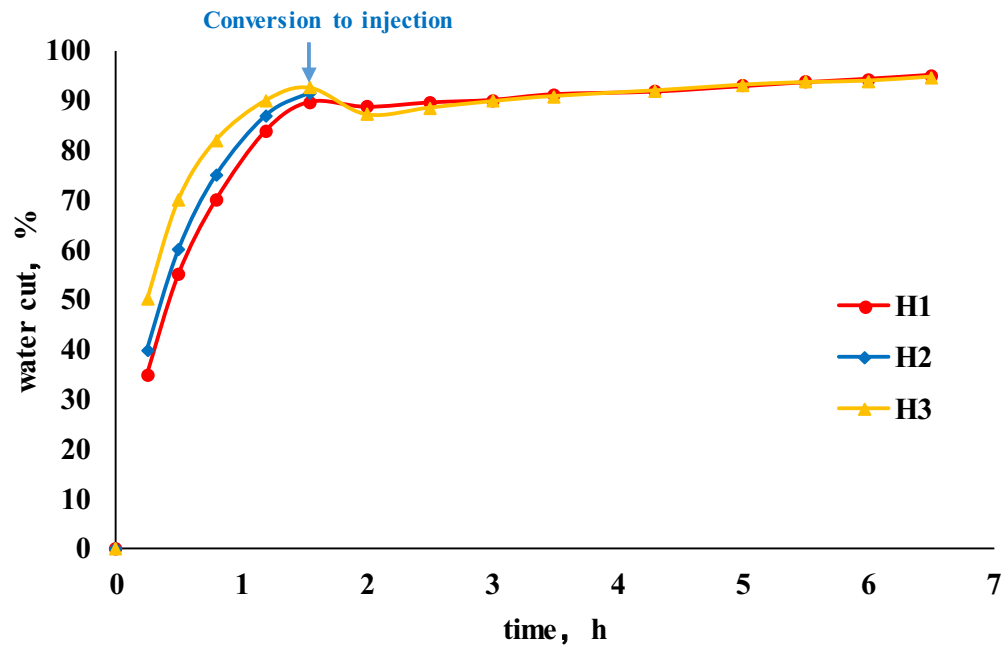

c. Water cut change of three horizontal wells in scheme 2 reservoir

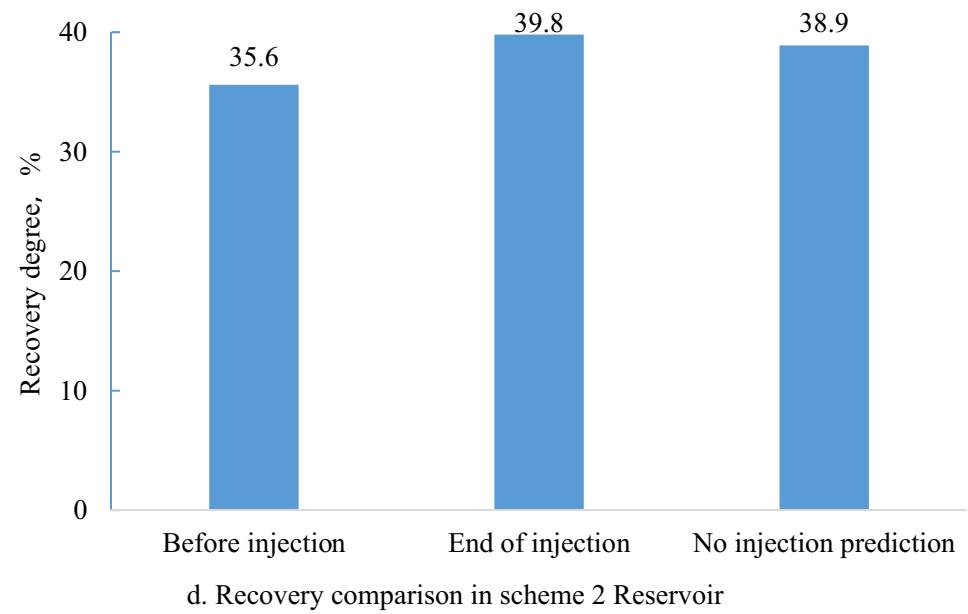


- Well H3: The changing trend of water cut is the same as that of well $\mathrm{H} 1$, but the water cut before the injection is higher than that of well $\mathrm{H} 1$, and the water cone-formed is also more giant;

- H2 (reinjection well): The water cone's internal water washing effect formed in well $\mathrm{H} 2$ has been significantly improved, which has a substantial lateral displacement effect on two adjacent wells and a good displacement effect on the remaining oil between wells.

- The recovery factor after injection is $39.8 \%$, which is slightly higher than $38.9 \%$ without injection.

Experimental scheme 3 (viscosity is $150 \mathrm{cp}$, with interlayer, see Fig. 15).

Before transfer:

- Well H1: Well H1 is entirely in the interlayer control area, the water energy is challenging to reach, and the water breakthrough time is very late;

- Well H3: After the bottom water bypasses the interlayer, well $\mathrm{H} 3$ starts to see water first, and the water cut rises rapidly;

- H2 (reinjection well): The water body continues to advance along the plane, the water breakthrough of well $\mathrm{H} 2$ is rapid, and the water content rises rapidly.

\section{After conversion:}

- Well H1: After the injection, the sweep range expands rapidly in both horizontal and vertical directions. Water breakthrough occurs in well H1, the water body advances along the upper part of the interlayer under the action of gravity, and a small bottom water coning occurs near well $\mathrm{H} 1$;

- Well H3: Because well H3 is close to the area without an interlayer, the water must pass through well $\mathrm{H} 3$ to enter the oil reservoir so that the area near well $\mathrm{H} 3$ is washed by water for a long time, and the water content rises rapidly;

- Well H2 (reinjection well): After reinjection, the degree of water washing near well $\mathrm{H} 2$ and well $\mathrm{H} 3$ is more substantial, and well $\mathrm{H} 1$ begins to see water, which indicates that the injected water will not only wash the existing channeling channel but also displace the area with insufficient energy to achieve the effect of the plane sweep.

- When there is an interlayer in the reservoir, the recovery factor after injection is $30.7 \%$, significantly higher than $24.8 \%$ without injection.

Experimental scheme 4 (viscosity $30 \mathrm{cp}$, no interlayer, well pattern densification, see Fig. 16).
Before transfer:

1. Due to the low viscosity of crude oil, the bottom water uplift is relatively uniform, and the distribution range of residual oil in the later stage of natural water flooding is small, and the sweep range is extensive;

2. Before injection, the water cut of each well rises slowly, the low water cut production period is longer, and the water cut rising law of every single well is quite different;

\section{After conversion:}

1. After reinjection, the lateral displacement of water is apparent. In the later stage of development, except for the corner, most areas are swept by the water, and the remaining oil exists in a small range;

2. After the well spacing is reduced, the inhibition effect of artificial water injection on water cut is not apparent, but the water cut of the reservoir and single well increases rapidly in the later stage of injection transfer.

After the well spacing of the low viscosity reservoir is reduced, the recovery factor reaches $46.1 \%$, which is higher than $38.9 \%$ of the non-infill scheme. After the infill well in a low viscosity reservoir is transferred to injection, the recovery factor is $45.6 \%$, which has little change compared with non-injection, and most of the cumulative production fluid is water.

\section{Conclusions}

Through the oil-water distribution map of the model, the following conclusions and understandings can be obtained:

1. For reservoirs with a viscosity of $150 \mathrm{cp}$. The recovery factor after water injection is slightly higher than before water injection. However, the recovery factor is lower than that without injection production. The reason is that the increment of injection conversion is limited to reduce one production well after injection conversion.

2. For reservoirs with a viscosity of $30 \mathrm{cp}$. The recovery factor after injection is $39.8 \%$, which is slightly higher than $38.9 \%$ without injection.

3. For reservoirs with a viscosity of $150 \mathrm{cp}$. In the case of the interlayer. The recovery factor after injection is $30.7 \%$, which is significantly higher than $24.8 \%$ without injection.

4. After the well spacing of the low-viscosity reservoir is reduced, the recovery factor reaches $46.1 \%$, which is higher than $38.9 \%$ of the non-infill scheme. After the infill well in a low viscosity reservoir is transferred to

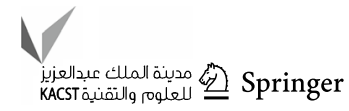


Fig. 15 Experimental scheme 3 analysis of experimental results

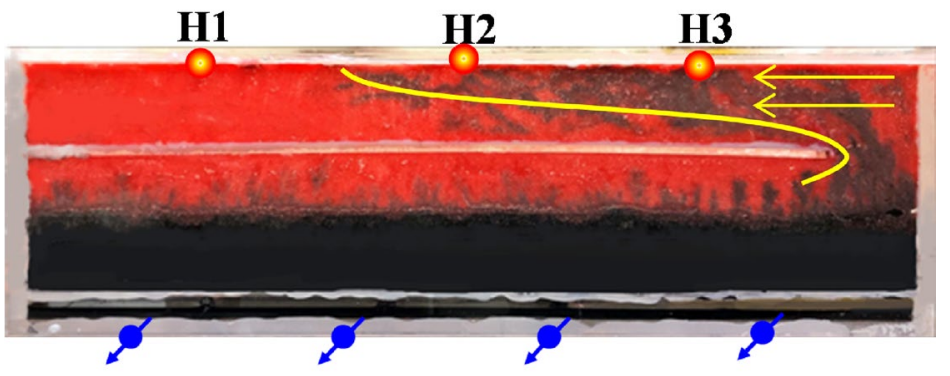

a. Oil saturation distribution before injection in scheme 3 Reservoir

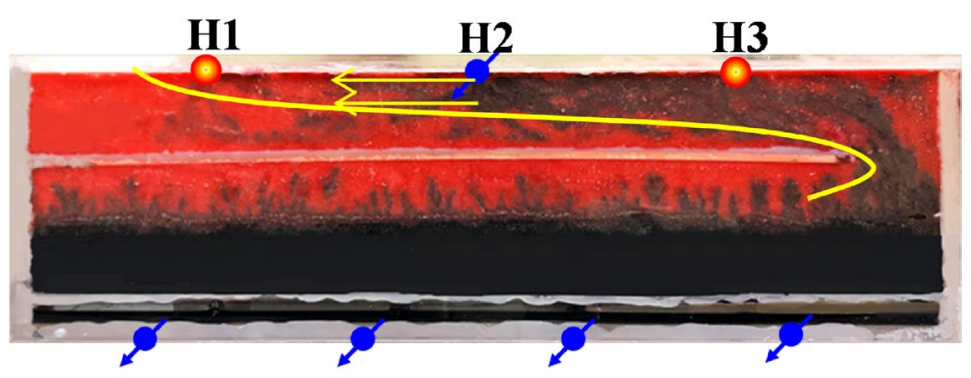

b. Oil saturation distribution map of scheme 3 reservoir after injection

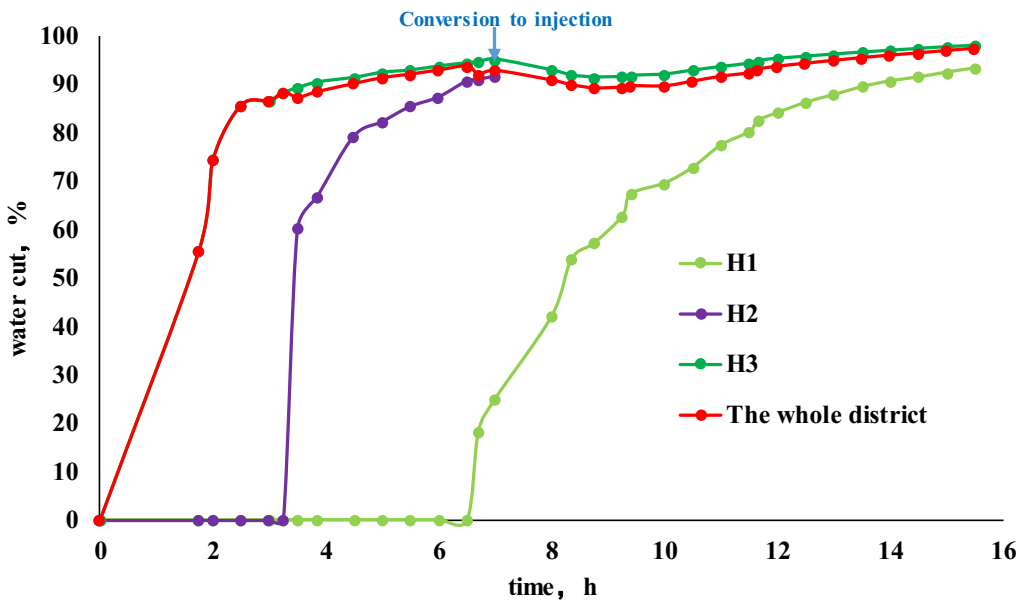

c. water cut change of three horizontal wells in scheme 3 Reservoir

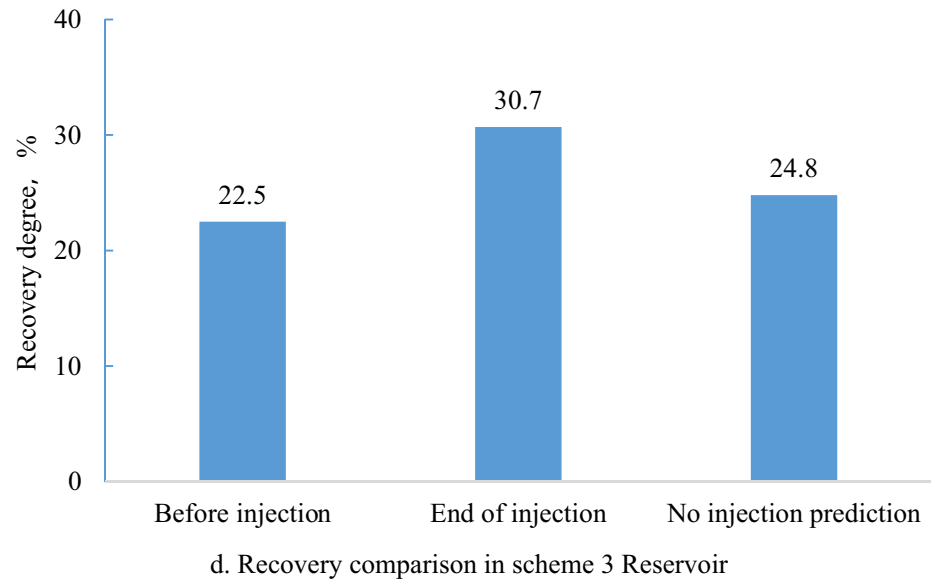


Fig. 16 Experimental scheme 4 Analysis of experimental results

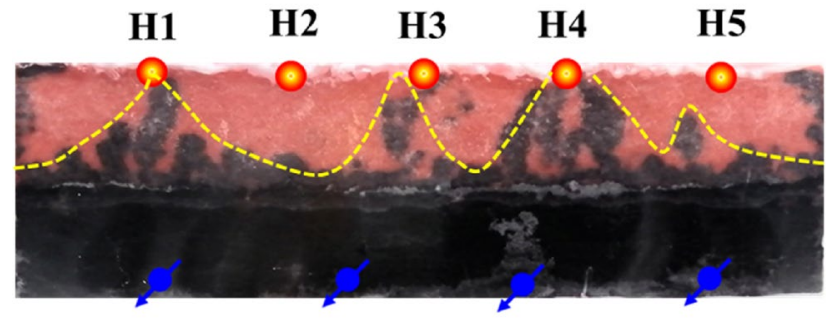

a. Oil saturation distribution before injection in scheme 4

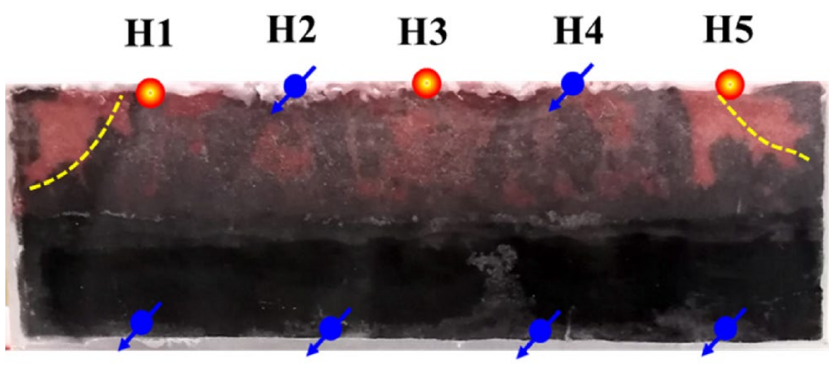

b. Oil saturation distribution map of scheme 4 after injection

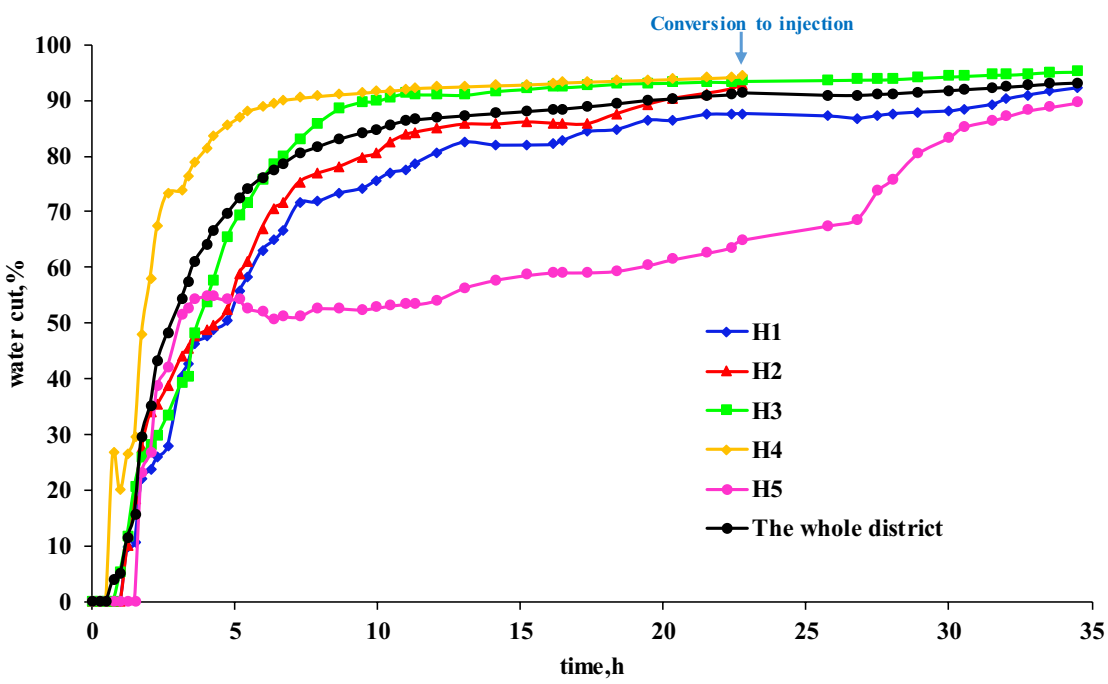

c. Water cut change of five horizontal wells in scheme 4

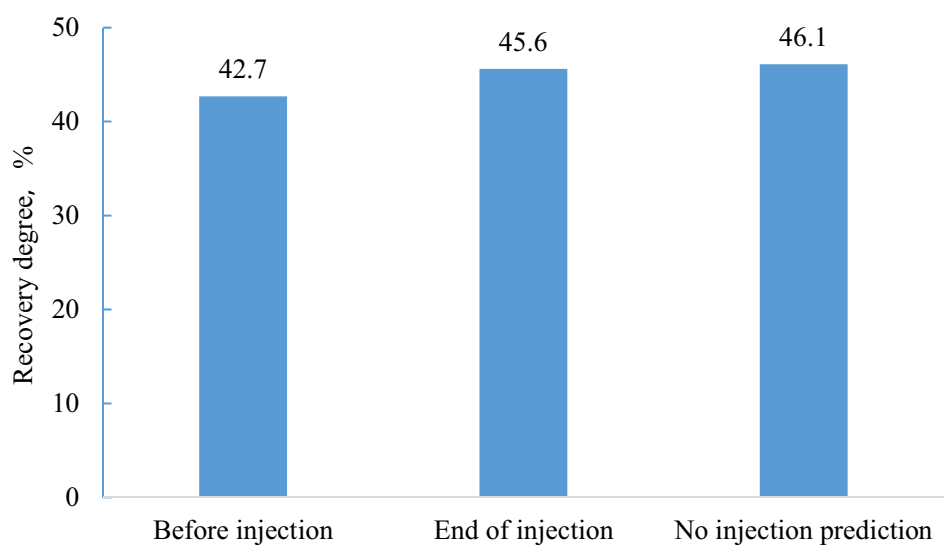

d. Recovery comparison in scheme 4 Reservoir 
injection, the recovery factor is $45.6 \%$, which has little change compared with non-injection, and most of the cumulative production fluid is water.

This study provides the basis for the proposal of production well injection conversion and the adjustment of production parameters in the highest water cut stage of a vital bottom water reservoir.

Funding The project is supported by the National Science and Technology Major Project During The 13th Five-year Plan Period "Bohai Oilfield Efficient Development Demonstration Project" (Number 2016ZX05058). The funders had no role in study design, data collection, analysis, decision to publish, or manuscript preparation.

\section{Declarations}

Conflict of interest To be used for non-life science journals.

Open Access This article is licensed under a Creative Commons Attribution 4.0 International License, which permits use, sharing, adaptation, distribution and reproduction in any medium or format, as long as you give appropriate credit to the original author(s) and the source, provide a link to the Creative Commons licence, and indicate if changes were made. The images or other third party material in this article are included in the article's Creative Commons licence, unless indicated otherwise in a credit line to the material. If material is not included in the article's Creative Commons licence and your intended use is not permitted by statutory regulation or exceeds the permitted use, you will need to obtain permission directly from the copyright holder. To view a copy of this licence, visit http://creativecommons.org/licenses/by/4.0/.

\section{References}

Alizadeh N, Salek B (2021) Waterflood optimization using an injector producer pair recovery factor, a novel approach. J Pet Explor Prod Technol 11:949-959. https://doi.org/10.1007/s13202-020-01072-3

An X, He Y, Xiong W et al (2008) Study on horizontal well potential tapping technology in the middle and late stage of bottom water reservoir development. J Oil Gas Technol (j JPI) 30(1):318-321

Archer RA, Yildiz TT (2001) Transient well index for numerical well test analysis. In: SPE technical conference and exhibition. Society of Petroleum Engineers, pp 150-159

Cheng L, Lang Z, Zhang L (1994) Reservoir engineering problem of horizontal wells coning in bottom-water driven reservoir. J China Univ Pet (nat Sci Ed) 18(4):43-47
Cheng Q, Feng W, Peng X et al (2012) Discussion on flooding pattern for bottom water reservoirs driveling by water-injection. Oil Drill Prod Technol 34(3):91-93

Escobar F, Djebbar T. (2002) PEBI grid selection for numerical simulation of transient tests. SPE Western Regional/aapg Pacific, pp 321-334

Henley DH, Owens WW, Craig FF et al (1961) A Scale-model study of bottom-water drives. J Pet Technol 13(1):90-98

Islam MR, Yin H (1999) Exploitation of crude oil in bottom water reservoir. Energy Sav Pet Petrochem Ind 1:6-8

Jiang Q (2013) 56 Waterflooding development effect evaluation of sandy conglomerate bottom water oil reservoir of Lei 64faultedblock. Pet Geol Eng 27(1):56-58

Le P (2013) Productivity prediction and water cresting and coning dynamic of branched horizontal well in bottom water reservoir. Dissertation, Southwest Petroleum University

Long M, Yanan Xu, Dengfe Yu et al (2017) Quantitative optimization of water injection for Bohai heavy oil reservoir with bottom water: a case study of the west block of QHD32-6 oilfield. China Offshore Oil Gas 29(04):91-97

Ning X, Zhang W, Wang Z et al (2004) Water-flood recovery in huge pay layer botton water reservoir. Fault Block Oil Gas Field 11(4):30-32

Ogbeiwi P, Aladeitan Y, Udebhulu D (2018) An approach to waterflood optimization: case study of the reservoir X. J Pet Explor Prod Technol 8:271-289. https://doi.org/10.1007/s13202-017-0368-5

Puchyr PJ (1991) A numerical well test model. In: SPE, pp 225-233

Ragunathan T, Zaqwan J, Wood CD (2021) The rheological behavior of crude oil in the presence of palm oil additives. J Pet Explor Prod Technol. https://doi.org/10.1007/s13202-021-01193-3

Wang Y (2015) Study on productivity evaluation and optimal design for horizontal wells in bottom water reservoir. Dissertation, China University of Petroleum (East China)

Zhang W, Long M, Zhou Y et al (2020) Waterflooding development chart establishment and application for the oil reservoir without interbed. Special Oil Gas Reserv 27(2):115-119

Zhao F (2018) The study on development law and effective drive strategy of horizontal well in bottom water reservoir. Dissertation, China University of Petroleum (East China)

Zheng S, Corbett P, Stewart G, et al. (1996) The impact of variable formation thickness on pressure transient behavior and well test permeability in fluvial meander loop reservoirs. In: SPE technical conference and exhibition, pp 98-105

Zheng X, Zhong W, Duan H et al (2015) Feasibility study of waterflooding development for strong bottom water reservoir. Fault Block Oil Gas Fields 22(2):234-236,250

Publisher's Note Springer Nature remains neutral with regard to jurisdictional claims in published maps and institutional affiliations. 